\title{
Lettres inédites de Juliette Drouet à Victor Hugo, éditées par Marva A. Barnett et Gérard Pouchain
}

\section{Gwenaëlle Sifferlen}

\section{(2) OpenEdition}

1 Journals

\section{Édition électronique}

URL : http://journals.openedition.org/studifrancesi/531

DOI : 10.4000/studifrancesi.531

ISSN : 2427-5856

Éditeur

Rosenberg \& Sellier

\section{Édition imprimée}

Date de publication : 1 avril 2015

Pagination : 172-173

ISSN : 0039-2944

\section{Référence électronique}

Gwenaëlle Sifferlen, «Lettres inédites de Juliette Drouet à Victor Hugo, éditées par Marva A. Barnett et Gérard Pouchain », Studi

Francesi [En ligne], 175 (LIX | I) | 2015, mis en ligne le 01 avril 2015, consulté le 18 septembre 2020. URL : http://journals.openedition.org/studifrancesi/531; DOI : https://doi.org/10.4000/studifrancesi 531

Ce document a été généré automatiquement le 18 septembre 2020.

\section{(c) (i) (9)}

Studi Francesi è distribuita con Licenza Creative Commons Attribuzione - Non commerciale - Non opere derivate 4.0 Internazionale. 


\title{
Lettres inédites de Juliette Drouet à Victor Hugo, éditées par Marva A. Barnett et Gérard Pouchain
}

\author{
Gwenaëlle Sifferlen
}

\section{RÉFÉRENCE}

Lettres inédites de Juliette Drouet à Victor Hugo, éditées par Marva A. BARNETT et Gérard POUCHAIN, Publications des Universités de Rouen et du Havre, 2012, pp. 271.

1 Julienne Gauvain, dite Juliette Drouet, est principalement connue pour avoir été, pendant la majeure partie de sa vie, la plus fidèle compagne de Victor Hugo. Mais elle fut aussi, et surtout, une inlassable et prodigue épistolière qui écrivit quasiment tous les jours jusqu'à sa mort, pendant cinquante ans (1833-1883), une lettre au moins à son «cher poète». Si ces «restitus» ou "gribouillis quotidiens», comme elle les qualifiait elle-même, sont parvenus jusqu'à nous, c'est parce qu'ils furent précieusement conservés par Hugo qui les restitua, à la mort de Juliette, à son neveu Louis Koch.

2 Aujourd'hui dispersés, ils sont conservés dans différents sites belges et français comme la Bibliothèque nationale de France qui en racheta près de 17000 au peintre Louis Icart en 1969, la Maison de Victor Hugo à Paris, la Maison littéraire de Victor Hugo à Bièvres ou la Maison Vacquerie à Villequier, des bibliothèques, des médiathèques, des musées, mais aussi des collections particulières et enfin de prestigieuses universités américaines (Yale University Beinecke Library, Pierpont Morgan Rare Book Library, Harvard University Houghton Library, Syracuse University Library).

3 Cette correspondance est encore peu exposée au grand public; en effet actuellement, seules quelques centaines de lettres ont déjà été publiées dans des recueils version papier qui ont en général davantage privilégié les plus remarquables d'entre elles, que ce soit par leur style plus élégant ou parce qu'elles témoignaient d'événements importants et décisifs de la vie de Victor Hugo. 
Or la spécificité et l'intérêt de ce recueil sont de passer outre ces considérations puisqu'il s'agit de 105 pièces «américaines» inédites (de 1835 à 1878), qui viennent d'être retrouvées et publiées pour la première fois par Marva A. Barnett (auteur de Victor Hugo on Things that Matter), qui les a exhumées dans les bibliothèques américaines où elles étaient conservées, et Gérard Pouchain (co-auteur de la biographie de référence sur Juliette Drouet, parue chez Fayard en 1992), qui les a transcrites et annotées. Ces lettres sont précédées d'une brève introduction présentative suivie du protocole systématique de transcription et d'annotation (notes explicatives et manuscriptologiques), et enrichies d'un cahier iconographique rassemblant des scans, des photographies, des portraits de Juliette, Hugo et leurs proches. Les éditeurs ont en outre ajouté quelques repères chronologiques nécessaires à la bonne compréhension biographique et historique ainsi qu'un index des noms de personnes citées permettant des regroupements.

Parmi les lettres proposées, 6 appartiennent à la Pierpont Morgan Rare Book Library (années 1846, 1847, 1849 et 1851), 7 à l'université Yale (années 1846, 1847, 1849, 1850 et 1851), 44 à l'université de Syracuse (années 1835, 1850, 1872, 1874 et 1878), et 48 à l'université de Harvard (années 1846, 1847, 1848, 1849, 1850 et 1851).

6 En observant le tableau reproduisant le nombre de lettres par année, on remarque que le corpus s'étoffe au moment où Hugo s'engage en politique et où il est élu député, mais aussi lorsqu'il séjourne pour la dernière fois à Guernesey.

\begin{tabular}{|l|l|l|l|}
\hline Années & Nombre de lettres & Années & Nombre de lettres \\
\hline 1835 & 1 & 1850 & 12 \\
\hline 1846 & 3 & 1851 & 4 \\
\hline 1847 & 18 & 1872 & 1 \\
\hline 1848 & 10 & 1874 & 1 \\
\hline 1849 & 16 & 1878 & 39 \\
\hline
\end{tabular}

7 La lecture attentive de ces lettres permet d'observer rapidement l'émergence et la construction d'un modèle-type. Sur un feuillet de quatre pages d'environ 15 centimètres sur 9 entièrement rédigées recto-verso, Juliette Drouet écrit tout d'abord la date précise au quart d'heure près en en-tête, puis une apostrophe liminaire souvent originale suivie du compte rendu, du programme, des préoccupations de la journée passée ou à venir, et elle termine toujours par une conclusion amoureuse et une formule d'adieu, tantôt classiques, tantôt insolites et humoristiques. Sa signature enfin, Juliette, Juju, JJ, J, est presque systématique.

8 L'épistolière n'imaginait certes pas, lorsqu'elle envisageait sur le ton de la plaisanterie que la postérité s'emparerait peut-être un jour de sa correspondance, que ses états d'âme quotidiens trouveraient un écho si fort au Xxi ${ }^{e}$ siècle. En effet, que ce soit pour «le style Juju» en lui-même, réjouissant, spontané, sincère, hyperbolique, souvent humoristique, mélange de sublime et de grotesque, ou que ce soit pour son genre hybride à la croisée des chemins entre la correspondance, le journal personnel ou la 
conversation, le lecteur ne manquera pas d'être fasciné par ces incroyables preuves d'amour absolu que sont ces lettres «américaines».

9 Ce corpus est voué à rejoindre l'édition de l'intégralité des lettres de Juliette Drouet à Victor Hugo (environ 22000), effectuée par le Centre d'Études et de Recherche Éditer/ Interpréter de l'Université de Rouen sous la direction de Florence Naugrette, avec le conseil scientifique de Jean-Marc Hovasse, Gérard Pouchain, Chantal Brière, Guy Rosa et Françoise Simonet-Tenant. Après tout, Juliette Drouet ne jugeait-elle pas elle-même que «l'amour peut se mettre en plusieurs volumes, comme le génie» (lettre du 17 février 1841)? 